\title{
Reflexiones acerca de literatura marginal: la literatura pornográfica o de "consolación"*
}

\author{
Carolina Gutiérrez Ramírez ${ }^{1}$ \\ Universidad Andina Simón Bolívar (Ecuador)
}

\section{Resumen}

En el presente trabajo abordamos la condición ancilar de los textos "pornográficos", las dinámicas que se tejen en torno a ellos y la clase de relato que construyen, sus espacios de circulación y los imaginarios en juego en Cali (Colombia), en las décadas del sesenta y setenta, tomando como punto de partida la producción del escritor "marginal” Hernán Hoyos (Cali, 1931).

Palabras clave: cultura popular, literatura, pornografía, marginalidad, representación.

\begin{abstract}
In this paper we approach the ancillary condition of the "pornographic" texts, the dynamics interweaved around them and the kind of story that are constructed, the spaces of circulation and the imaginaries in Cali (Colombia), in the decades of the sixties and seventies, taking as a point of departure the production of the writer "marginal" Hernán Hoyos (Cali, 1931).
\end{abstract}

Keywords: popular culture, literature, pornography, marginality, representation.

\section{Algunas consideraciones sobre literatura "marginal"}

Ángel Rama no sólo ha señalado las bases desde las cuales se construyeron los análisis literarios en latinoamericana durante mucho tiempo, sino que también destacó los focos de producción

\footnotetext{
* "Reflections about marginal literature: the pornographic literature or that one of "consolation"".

Recibido: 18 de enero de 2013 - Aprobado: 24 de febrero de 2013.

${ }^{1}$ Historiadora de la Universidad del Valle. Magister en Estudios de la Cultura, con Mención Literatura Hispanoamericana de la Universidad Andina Simón Bolívar. Miembro del Grupo "Nación, Cultura y Memoria" de la Facultad de Humanidades de la Universidad del Valle. e-mail: muy_caro@yahoo.es
} 
literaria alterna a los cauces del canon: sus reflexiones sobre la literatura marginal y los canales de circulación de los textos son contundentes ante las actuales pesquisas que intentan dilucidar la relación entre literatura y sociedad. Así mismo, las precisiones del autor uruguayo sobre "las coordenadas mentales" o la "imaginería" que se desprende de los textos, y la relación reciproca de la producción literaria como reflejo de su época, y al mismo tiempo, como proyección y nueva elaboración que reconfigura la realidad, permiten entablar nuevos diálogos con textos relegados.

Varias de sus inquietudes críticas rebosan de entusiasmo ante las nuevas pulsiones del mercado y la industria, el engrosamiento de las principales ciudades, la apertura de canales y medios de comunicación, la entrada de las clases medias y populares en el escenario público, y en la misma línea, la irrupción de relatos que articulan realidades y sentidos no considerados por la literatura oficial. Luis Fayad (1994: 31) asegura que con la urbanización de América Latina, acentuada desde los años cincuenta, surgieron nuevos elementos, y a la vez, nuevos problemas culturales. La cultura urbana del continente se modificó, cambió de aspecto y formas, posibilitando, entre otras cosas, una cultura popular distinta. De allí que Fayad señale que en las obras literarias comiencen a aparecer distintas posibilidades creadoras de lenguaje.

Refiriéndose a "otras posibilidades de lenguaje", Rama (1985: 277) anota que la compartimentación de la literatura hispanoamericana se había organizado con base a dos principios metodológicos rectores. El primero reducía el material literario al campo de la escritura culta; el segundo, suponía una articulación evolutiva y gradual de la literatura. Esto pone de manifiesto la restricción a la que ha estado sujeto aquello que se entiende como "literario". El ensalzamiento de cierto tipo estético habría arrinconado y desdibujado relatos que no se ceñían a lineamientos estéticos cultos y que se configuraban respondiendo a otras necesidades, a otras expectativas. En "Las literaturas marginales y la crítica: una propuesta", Cornejo Polar (1986: 93) advierte que el sistema literario hegemónico dispone para su producción y reproducción de los atributos de la institucionalidad educativa y cultural, y globalmente, de los servicios ofrecidos por el orden social todo, mientras que los sistemas marginales no cuentan más que con la potencialidad de los grupos que se expresan a través de ellos, que precisamente son grupos social y étnicamente deprimidos.

Como anota Cornejo Polar, debe pensarse entonces que una gran brecha de obras y autores fueron desatendidos por los canales 
oficiales de apreciación literaria. Rama (1996: 122), por su parte, afirma que esta concepción cultista de la literatura ayudó a fortalecer la idea de un conglomerado unitario. Tal disposición no sólo pone en presente el estatuto de peculiaridad o rareza que enviste las producciones periféricas, sino que, al mismo tiempo y de manera lamentable, socava los registros, las dinámicas y las alternativas estéticas de las "subliteraturas". En su libro Las contraliteraturas, Mouralis (1978: 6) sostiene que el conjunto de obras que una tradición cultural incluye en lo que considera su literatura -y muy a menudo, como la literatura- no es una colección, una serie, una enumeración o un catálogo, sino un sistema. En otras palabras, aquello que se denomina como literatura canónica no sólo ha logrado desplazar a la literatura marginal, sino que parece estar ligada a una jerarquización de valores morales e ideológicos que organiza y selecciona qué tipo de obras literarias son dignas de memorabilidad y cuáles son merecedoras de difusión institucional (actividad que al tiempo que selecciona, restringe).

De estas discusiones, según parece, debe valorarse con la misma medida la reflexión sobre el texto como dispositivo catalizador, es decir, no sólo recupera la realidad que le precede, sino que arroja -y propone- formas de comprensión e interpretación sobre aquello a lo que se refiere. Explica Rama (1985: 290) que tanto el discurso lingüístico como el "imaginario social" se recuperan en el texto literario, en una síntesis que, habiéndolos devorado, los devuelve a la sociedad como una totalidad inescindible. Esta dinámica del texto indica que si el texto puede albergar una función performatica -la cual recoge y traslada incesantemente formas de comprensión de la realidad que, paradójicamente, convierten al texto en más que una reproducción de la realidad-, la literatura tiene una singular forma de apropiarse del contexto, pero también de imponerse ante él. De allí que resulte valiosa la precisión de Rama: "Todo análisis de literatura y sociedad parecería proponer una doble y simultanea lectura: la de la literatura y la de la sociedad en que ella se produce" (284).

Más que hacer un rastreo del tipo de sociedad en la que se produce el texto -en este caso, el relato marginal-, interesa comprender qué elementos sociales figuran en el texto y de qué manera son esbozados. Conviene estar atento no sólo al tipo de relato que se articula, sino a su forma precisa de enunciación. ¿Cuál es la cosmovisión que se desprende de la propuesta literaria de estos textos? ¿Cuáles son sus canales de circulación? ¿Cuáles son las particularidades de la materialidad de estos libros? Buscando dar coherencia a las anteriores afirmaciones y preguntas, debe ilustrarse cómo se ciñen a 
formas concretas de producción, circulación y dinámicas particulares de consumo. En este caso, es válido traer a colación, por ejemplo, la producción de un escritor como Hernán Hoyos (Cali, 1929).

En la segunda mitad del siglo XX, fue uno de los autores más leídos en el panorama literario colombiano; no obstante, sus relatos de alto contenido sexual hicieron que se le catalogara rápidamente como un escritor "pornográfico", cuya lectura era sinónimo de vergüenza y reprobación social. La continua publicación de sus obras, no obstante, así como la constante reedición de sus publicaciones, comprueba un acogimiento por parte de los lectores. El escritor colombiano ha publicado, entre 1960 y 1975, veintitrés libros que oscilan entre novelas de terror y misterio, relatos de humor, testimonios, reportajes, crónicas sexuales y novelas pornográficas. Esta constatación, que se podría pasar sin más, es bastante significativa, ya que evidencia el repertorio literario por el que se ha movido el autor, para después concentrarse en lo que se ha denominado como "literatura marginalizada", una literatura moralmente intrépida: la pornográfica.

Puede decirse que es bastante factible estudiar la pornografía como parte de un sistema cultural, teniendo en cuenta los libros que circula en la sociedad de una época determinada. De allí que, como se afirmaba anteriormente, deba prevalecer la descripción física del texto, los sitios y estrategias de venta, las temáticas expuestas y otros detalles relevantes para comprender cómo el "mensaje" encaja con el medio. Tal como sucede con la literatura "canónica" o "culta", los textos "marginalizados" interiorizan una noción de verdad: los relatos pornográficos comportan una idea general de la vida cotidiana, de las incertidumbres y los anhelos de la clase popular, pero, sobre todo, de sus inquietudes y vivencias en el campo sexual. También es necesario señalar que los relatos pornográficos han estado insoslayablemente vinculados al espacio urbano y a lo que en éste ocurre.

Los pequeños sucesos del diario vivir, la rutinaria diligencia y el encuentro fortuito hacen así parte de la obra de Hernán Hoyos. Es la descripción de algunos días, de ciertos meses de la vida de sus personajes, lo que le interesa: se trata de una cotidianidad descrita minuciosamente. Al tratar de saturar al lector con detalles: las casas, sus colores, las calles, los olores, los sabores, sonidos y formas, las descripciones de Hoyos pueden resultar desmesuradamente intensas. Pero, así mismo, en su transitar por Cali (que, en este caso, es el referente geográfico del autor), ha sabido apropiarse de sus andenes y avenidas. Cada calle resulta un espacio geográfico y 
simbólico. Resulta particularmente acertada la reflexión sobre el espacio urbano realizada por el filósofo y semiólogo colombiano Armando Silva (1992): "Nombrar el territorio es asumirlo en una extensión lingüística e imaginaria; en tanto que recorrerlo, pisándolo, marcándolo en una y otra forma es darle entidad física que se conjuga, por supuesto, con el acto denominativo. Estos dos ejercicios, denominar y recorrer, han de evolucionar hacia el encuentro de la región llamada territorio" (48).

Al describir hasta la saciedad el espacio urbano y sus personajes, las calles y los tugurios, Hoyos esboza en sus relatos una prosopografía de la ciudad que va de la mano de un croquis de los conflictos y dinámicas de la sociedad que describe. De Certeau (2000) da luces al respecto: "Los relatos efectúan un trabajo que, incesantemente, transforman los lugares en espacios o los espacios en lugares. Organizan también los repertorios de relaciones cambiantes que mantienen unos con otros". (130). Semejante certeza está en evidente diálogo con las reflexiones a las que llega Rama (1985: 289), cuando explica que la literatura genera un discurso sobre el mundo, pero ese discurso no pasa a integrar el mundo, sino la cultura de la sociedad, siendo una parte de la vasta malla simbólica mediante la cual los hombres conocen y operan sobre el mundo.

\section{Cali: la ciudad y el porno}

A pesar del aura peyorativa que rodea la literatura marginal, entendida como categoría literaria ubicada al margen, o en la frontera, de la literatura "tradicional", algunos autores han advertido que reproduce el auténtico juego intertextual de la sociedad, ya que las interacciones se dan continuamente entre lo oral y lo escrito, entre lo letrado y lo iletrado, entre lo visual y lo auditivo. En conclusión, podría hablarse de un juego intercultural que se hace más visible que en cualquier otra parcela de lo literario (García de Enterría, 1995: 10). Al reflexionar sobre la partición tradicional que opone lo culto y lo popular (en nuestro caso, lo segundo como el conjunto de textos vendidos mediante venta ambulante), Chartier (2002:33-4) define lo popular en contraposición a aquello que no es. Así lo popular tendrá un cuerpo bien diferenciado de la literatura erudita y letrada, y debe decirse que sus representaciones comenzarán a circular cada vez más con mayor impulso debido a la utilización reciente de nuevas tecnologías tipográficas y de impresión en el casco urbano.

En las décadas del sesenta y setenta, Cali empieza a convivir con material pornográfico en quioscos, corredores urbanos y pequeñas librerías del centro. La atmósfera citadina se trastoca con el ritmo 
habitual que proporciona el material corruptor vuelto lícito, conocido y tolerado. "Las cosas comienzan a torcerse a partir del momento en que, gracias a los medios de difusión modernos, tales representaciones comienzan a circular fuera del pequeño círculo, y los más pobres también pueden disfrutarlas", afirma Ogien (2005: 73) sobre los síntomas que son notorios en las sociedades que conviven con la pornografía. Y, sin embargo, con la literatura pornográfica, masificada y consumida, el tránsito urbano se ve trastocado por las dinámicas que su comercio supone.

En un principio, como se ha dicho, los libros de Hernán Hoyos fueron un asunto de ocultación -como problema social, la pornografía era considerada un fenómeno amorfo de la cultura de masas-, al poner en circulación los bajos fondos de la sociedad caleña: el homosexual, el proxeneta, la prostituta, la lesbiana, la ninfómana. Considerada como amenaza, la pornografía resultaba aún más grave cuando se retrataba detalladamente el comportamiento obsceno de la población que era al mismo tiempo su consumidora. Ente 1965 y 1975, las novelas pornográficas escritas sobre personajes de la ciudad, y ofrecidas por vendedores ambulantes del centro, abandonaron los anaqueles ocultos del librero de Santa Rosa de Lima y se acomodaron en los andenes y escaparates del centro urbano. Al tránsito citadino se adhirió un nuevo producto que fue ganando espacio: el espacio del porno.

El porno no es una cosa, una imagen, sino la "representación visual” de esa imagen y la experiencia de su recepción. Y sólo puede darse si el sujeto y el objeto se encuentran en el lugar adecuado: el de la "violación deliberada" del tabú. En último término, el porno es la experiencia de una representación en un sitio: el sitio de la transgresión (Barba \& Montes (2007: $63)$.

Al incluir estos hábitos de lectura (o al menos, la rutina de su observancia en el mercado y la posibilidad de su compra) y las dinámicas características de la convivencia con un novedoso y polémico material cultural, la ciudad y sus habitantes incursionan en una esfera que tiene al sexo como opción de entretenimiento y esparcimiento cultural. La "ciudad mezcla hábitos, percepciones, historias", a decir de Silva (1992): “[...] es precisamente en la fusión de todas estas intermediaciones y costuras, como va aflorando la propia urbanidad o personalidad colectiva de la ciudad" (62). Como toda mercancía, el libro circula y delinea sus recorridos. Luis Alfonso Chavarro (1992: 39), en su estudio sobre la circulación del libro de publicación masiva en Cali, afirma que en las décadas de los sesenta y setenta hubo en grado ascendente un circuito o red del libro que se 
percibía en el mapa local, y que el autor ha denominado "Corredores del Centro", en el que predominaba el tipo de literatura popular. Así mismo, alude a librerías menores en el centro de la ciudad, al lado de la Plaza de Caicedo, o cerca a la Gobernación, algunas de más cobertura en la denominada zona del "Cali Viejo".

Chavarro va más allá y especifica que en tales espacios este tipo de libros, que denomina "literatura de consolación", habría de causar un gran impacto en el sector editorial, al ser de fácil venta, por su bajo costo y deleitable temática que ofrece una nueva forma de placer (40). Esta literatura de consolación, aludiendo a la literatura popular que recrea la vida sexual de sus personajes, toma un nuevo giro: el material pornográfico, que a bajo costo circulaba en el comercio de saldos, es impulsado con las nuevas tecnologías tipográficas de que hacía gala la ciudad. Razón tiene Michel de Certeau (2000), cuando se refiere al espacio "corporal" y al sistema mecánico: "esta maquinaria transforma los cuerpos individuales en un cuerpo social [...] la imprenta representa esta articulación del texto sobre el cuerpo por medio de la escritura" (129).

No obstante, las publicaciones de las novelas pornográficas de Hernán Hoyos no suponen ningún refinamiento en la materialidad del libro. Durante gran parte de la década del sesenta, se trató de publicaciones que vivían en el reino de los libros de saldo o en el depósito de los libros raros. Esta edición económica supuso escasa atención en la redacción del texto, en su coherencia y ortografía; se evidencia también en ella la poca exigencia en cuanto a la preparación del estilo del formato; y por último, aunque más revelador, el material que se utilizaba en la carátula y contracáratula (cartón de baja gama) delata las necesidades comerciales de los editores del momento, el imaginario que subyace en torno a un género "menor", y en general, el estatus que da el editor al libro "pornográfico". Andrés Barba y Javier Montes (2007), en La ceremonia del porno, apuntan sobre el estatus que ha envestido al libro porno:

El porno se concibe y consume en formatos rudimentarios reducidos a la mínima expresión narrativa y formal [...] ver porno es fácil: quizá no haya nada más llevadero y más fácil entre los estímulos que ofrece nuestra sociedad del espectáculo [...] se suele pensar en el porno como género perezoso y grado cero de la representación, como el más rudimentario de los géneros de ficción al que pueda optar el más rudimentario de los consumidores (17). 
Uno de los atractivos de este tipo de material fueron las particulares ilustraciones de novelas y relatos que hicieron inequívoca la temática que allí se planteaba. Es posible que estas ilustraciones -acompañada por los módicos precios con los que se ofrecían al público- reforzaron su apetencia en el mercado, ya que le daba al material un tono divertido, fresco, y sobre todo, pícaro. "El título dado al libro dice desde su entrada su contenido o, más precisamente, lo que el público de compradores potenciales debería creer que es su contenido", explica Chartier (2002). "Se trataría, entonces, de hacer el título lo más extravagante y sugerente posible. El título reforzado por la carátula daría una idea inequívoca del contenido del libro" (183). En varias ocasiones, Jesús Martín-Barbero (2003: 136), se ha referido a la importancia del título y todo lo que recae en su contundencia. El autor dirá, refiriéndose al mercado, el medio y el mensaje, que se trata de textos que salen a buscar sus lectores en la calle, y que presenta una hechura en la que el título es reclamo y motivación, publicidad. Al título sigue un resumen, que proporciona al lector las claves del argumento o las utilidades que le presta, y un grabado, que explota ya la "magia" de la imagen².

Es así que en la mayoría de los casos se trataba de viñetas pícaras ilustradas por reconocidos caricaturistas de la ciudad como, por ejemplo, Luis E. López (caricaturista del diario El País) y el autodenominado "Castillo" (quien sería más adelante caricaturista exclusivo del diario El Caleño). En algunas ocasiones se trató de mezquinas encuadernaciones que aglutinaban una serie de fotografías pícaras recortadas por el propio autor o, en otros casos, se publicaban carátulas cuyas imágenes ilustraban inequívocamente el tema del libro, en algunas de ellas no se protegían las zonas pudendas de las caricaturas. De esa manera no hubo que hacer mucho esfuerzo para encontrar el libro pornográfico: si no es el título, era la imagen lo que delataba el contenido de los libros de Hoyos. Como ejemplo, reproducimos las siguientes carátulas que dan cuenta del tipo de caricatura utilizada:

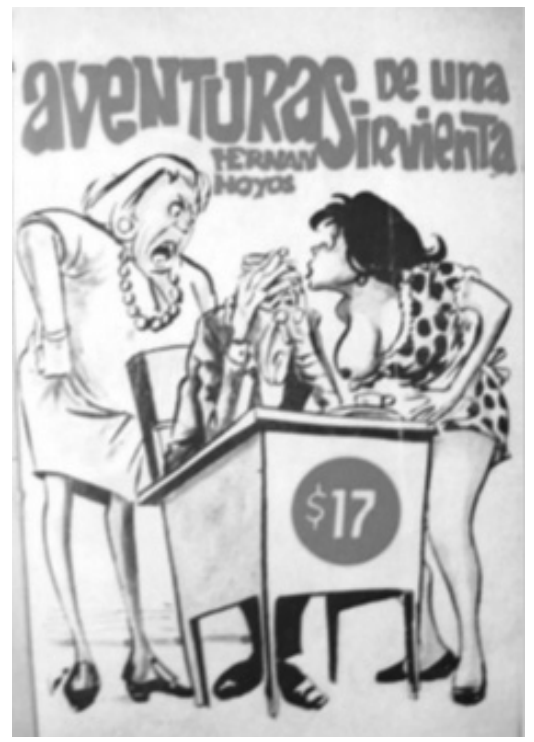

PORTADA 1. Aventuras de una sirvienta, Cartón baja gama (16.5 x $12 \mathrm{~cm})$, Cali, Ediciones Exclusivas, 1970.

2 Jesús Martin-Barbero, De los medios a las mediaciones. Comunicación, cultura y hegemonía, Bogotá, Unidad Editorial del convenio Andrés Bello, 2003, p. 136. 


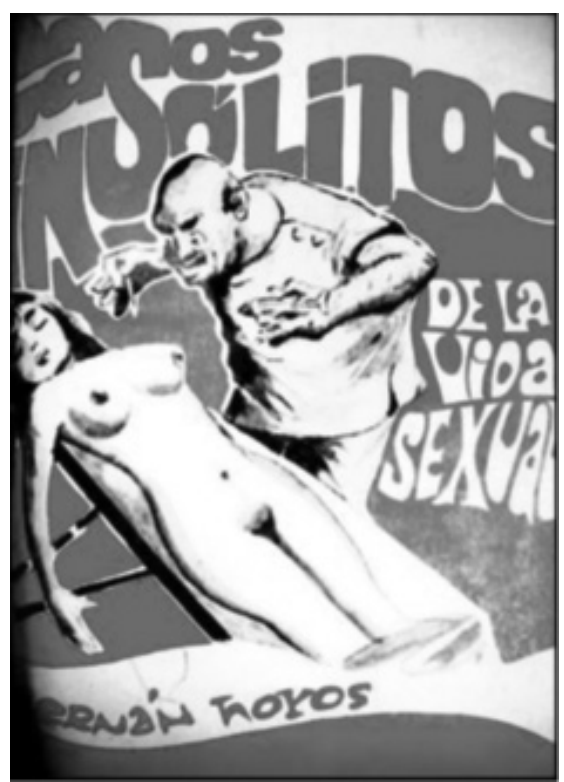

PORTADA 2. Casos insólitos de la vida sexulal, Cartón baja gama (16.5 x $11.5 \mathrm{~cm})$, Cali, Ediciones Exclusivas, 1971.

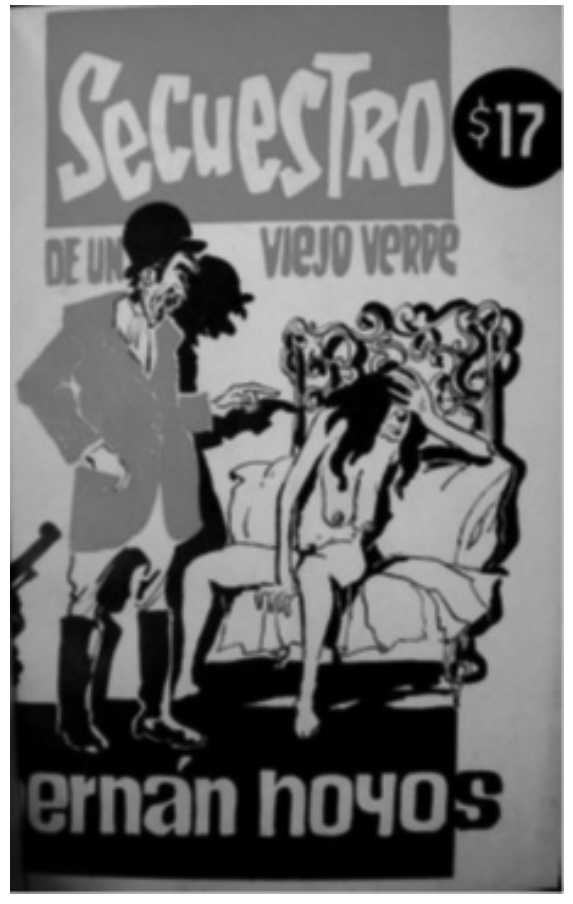

PORTADA 4. Seculestro de un viejo verde, Cartón baja gama (17 x $11.5 \mathrm{~cm})$, Cali, Ediciones Exclusivas, 1973.

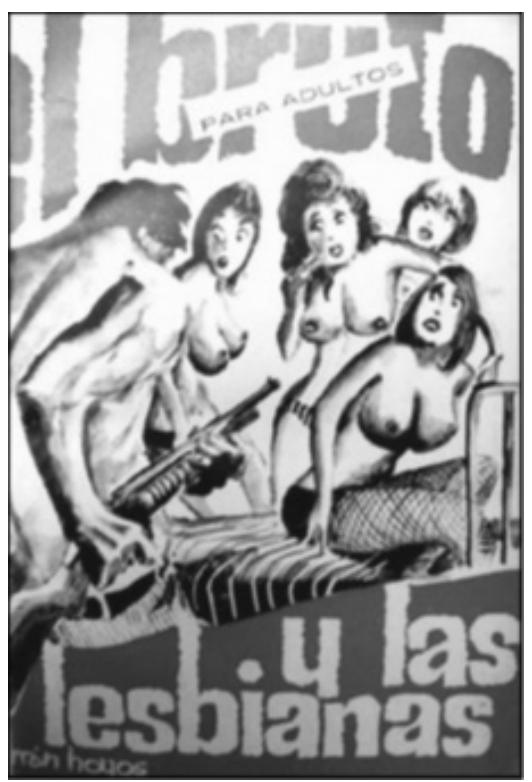

PORTADA 3. El bruto y las lestianas. Cartón baja gama (16.5 x $12 \mathrm{~cm})$. Cali: Ediciones Exclusivas. 1971.

Entonces, tanto lo llamativo de los títulos de Hoyos, como lo sugestivo de sus imágenes, pudo ser una combinación certera de la fórmula de su éxito comercial. Sumado a esto, algunas de sus publicaciones traían ilustraciones internas que reforzaban el episodio que se estaba relatando. Aun así, lo cierto en todo esto es que, paradójicamente, y tal como ya había destacado MartínBarbero (2001: 91), estos textos colocan en evidencia que el consumo no es únicamente reproducción de fuerzas, sino lugar de producción de sentido, de una lucha que no se agota en la posesión, ya que es el uso el que da forma social a los productos, al inscribir en ellos demandas y dispositivos de acción que movilizan las 
diferentes competencias culturales. De tal manera que la reflexión no puede quedarse únicamente en la descripción de los espacios de circulación y de repliegue de este tipo de material, sino que, sobre todo, urge también preguntarse por los usos que dan los lectores a este tipo de textos. Aunque es claro que la literatura "pornográfica" por sí sola da cuenta de unas dinámicas particulares: sector preciso de venta, público claramente determinado, estrategias de venta particulares y demás, debe ante todo comprenderse lo que desde hace algún tiempo advertía Darnton (2003): "Es necesario leer la pornografía por lo que dice sobre mentalidades que ya no existen" (85). Así mismo, es imperioso comprender que la pornografía no es un fenómeno ahistórico, y que, como bien es sabido, la lectura en apariencia pasiva y sumisa es, a su manera, inventiva y creadora (Chartier, 1995: 130).

Por último, el universo sexual de la época se representó en ese gran acuario que es la obra del autor colombiano, abundante en descripciones sexualesy en episodios de la cultura popular que fueron formando un sistema de referencias. En este punto es necesario recordar que Ángel Rama (1996: 126) premonitoriamente señalaba que la literatura se desarrollaba por cauces diversos, paralelos, siguiendo vericuetos y originales estructuraciones que deben recomponerse a través de un discurso interpretativo. Tal certeza de Rama propicia otra: la literatura marginal responde a mecanismos mentales, formas asociativas, construcciones ideológicas que son el patrimonio de ciertas sociedades (123). Esta reflexión del pensador uruguayo no puede tomarse a la ligera. Propicia -desde la época de la publicación de su obra hasta nuestros días- una mirada menos sesgada y más conciliadora con las diversas producciones literarias latinoamericanas. Pero también propicia una mirada acrisolada del devenir literario de América Latina.

Ángel Rama (1985), desde un principio, promovía que la "primera tarea critica de esta revisión generalizada, consistiría en recuperar la totalidad creadora de la cultura literaria hispanoamericana, sin apelar a las rejillas establecidas [...] operar con la virginidad de la mirada que se conquista cuando se hace frente al fluir de la realidad" (281). De allí que no sólo no se deben despreciar tales propuestas, sino que, de modo generoso y vinculante, su proposición teórica posibilita nuevos rumbos investigativos en el campo de la crítica literaria. Hoy, con más urgencia, están las bases para empezar tareas más integradoras que creen puentes entre los estudios sobre la cultura y la disciplina literaria. Estas investigaciones representarán solo un primer paso: pasos que seguramente serán poco firmes; sin 
embargo, en ningún momento se deberá dudar de la relevancia de esta tarea.

\section{Bibliografía}

Barba, A. \& Montes, J. (2007). La ceremonia del porno. Barcelona: Editorial Anagrama.

Cornejo Polar, A. (1986). "Las literaturas marginales y la crítica: una propuesta”. En Saúl Sosnowski. (Comp.). Augusto Roa Bastos y la producción cultural americana. Buenos Aires: Ediciones de la Flor.

Chartier, R. (2002). El mundo como representación. Historia cultural: entre práctica y representación. Barcelona: Gedisa.

(1995). Sociedad y escritura en la Edad Moderna. La cultura como apropiación. México: Instituto de Investigaciones Mora.

Chavarro, L. A. (1992). La circulación del conocimiento a través del libro de publicación masiva y su incidencia socio-cultural en Cali. Trabajo de grado, Santiago de Cali, Universidad del Valle, Facultad de Ciencias Sociales y Económicas, Departamento de Sociología.

Darnton, R. (2000). El coloquio de los lectores: ensayos sobre autores, manuscritos, editores y lectores. México: Fondo de Cultura Económica.

De Certeau, M. (2000). La invención de lo cotidiano. 1. Artes de hacer. México: Universidad Iberoamericana.

Fayad, L. (1994). "Cultura popular urbana en la nueva literatura”. En Karl Kohut. Literatura colombiana hoy. Imaginación y barbarie. Madrid, Iberoamericana.

García de Enterría, M. C. (1995). “Literatura popular”, Anthropos, n¹66/167 (Mayo-Agosto), Barcelona.

Martin-Barbero, J. (2003). De los medios a las mediaciones. Comunicación, cultura y hegemonía. Bogotá: Unidad Editorial del Convenio Andrés Bello.

. (2001). Al sur de la modernidad. Comunicación, globalización y multiculturalidad. Pittsburgh: Serie Nuevo Siglo.

Mouralis, B. (1978). Las contraliteraturas. Buenos Aires: El Ateneo.

Ogien, R. (2005). Pensar la pornografía. Barcelona: Paidós.

Rama, A. (1985). "Sistema literario y sistema social en Hispanoamérica”. En La actual crítica literaria hispanoamericana. Caracas: Universidad Central de Venezuela.

. (1996). "Literatura y clase social". En Saúl Sosnowski. (Ed.). Lectura crítica de la literatura americana. Inventario, invenciones y revisiones. Caracas: Ayacucho.

Silva, A. (1992). Imaginarios urbanos. Bogotá: Tercer Mundo Editores. 
